\title{
A HISTÓRIA DO CORPO: OS PRINCIPAIS EIXOS DA PESQUISA EM HISTÓRIA DA SAÚDE (FRANÇA, 1970-2000)
}

\author{
HISTORY OF THE BODY: MAIN AXES OF RESEARCH ON HISTORY OF \\ HEALTH (FRANCE, 1970-2000)
}

Jean-Pierre Goubert*

\begin{abstract}
Goubert J-P. A história do corpo: os principais eixos da pesquisa em história da saúde (França, 1970-2000). Rev Bras Crescimento Desenvolv Hum. 2006;16(1):97-102.

Resumo: Este artigo descreve como, tendo emergido nos últimos trinta anos, a pesquisa em História da Saúde na França foi marcada por quatro grandes direções de pesquisa: história dos profissionais da saúde, história das doenças, história dos hospitais, história das mentalidades. Apresenta o estado da arte em cada uma dessas direções durante estas décadas. Finaliza apontando para a dificuldade em seu reconhecimento como especialidade separada devido à abrangência de seu tema: o corpo.
\end{abstract}

Palavras-chave: História. Saúde. Profissionais da saúde. Doenças. Hospitais. Mentalidades. França.

\section{História da medicina e história da saúde}

Academicamente falando, na França existem apenas histórias separadas: a da medicina, a das ciências médicas ou ainda a da farmácia. Por causa disto, a história da saúde / doença apareceu apenas recentemente, surgindo, na França, no decênio de 1960. Será que a explicação para essa lacuna estaria em que os historiadores profissionais não dispõem, na França, de instituições específicas nem cadeiras universitárias consagradas à história da saúde, diferentemente do que ocorre, por exemplo, na Alemanha, na Suíça ou na Espanha? Está aí algo surpreendente que pede por uma explicação. Esta estaria na divisão da saúde, quer como uma questão em que cada um responde segundo a sua história, segundo o sentido que dá à vida, quer como o bem supremo de que todo mundo fala, cada qual à sua maneira. Nesta medida, nem a saúde nem a história da saúde são uma especialidade mas sim, uma generalidade.

Na longa duração, que prossegue até os nossos dias, a história da medicina permaneceu o apanágio do corpo médico. Desta maneira, precisaria ser médico para fazer a história da medicina, assim como apenas padres poderiam redigir uma história da Igreja.

Atualmente, na França, existem duas cátedras de história da medicina: uma ocupada por um professor de medicina (em Paris), a outra, por uma historiadora, ainda em Paris, embora existam também orientações de trabalhos acadêmicos na IV sessão da Ecole Pratique des Hautes Etudes (EPHE) e na Ecole des Hautes Etudes en Sciences Sociales (EHESS), assumidas por historiadores, sempre em Paris.

Uma outra orientação francesa, que se mantem até hoje, quer que a epistemologia, e portanto a história do saber médico, seja uma

\footnotetext{
Prof Dr em História da Saúde da Ecole des Hautes Etudes en Sciences Sociales, Paris V, França. Centre de Recherches Historiques EHSS 54 Bl Raspail 75006 Paris França goubertjpg@aol.com - Trad.: Elaine Pedreira Rabinovich.
} 
exclusividade dos filósofos e ocorra a partir da história das idéias e dos conceitos. Ora, a saúde é um objeto além do saber, sendo tanto um conceito vulgar quanto uma noção filosófica, e não uma coisa científica em que ambos emerjem do Conhecimento. Assim, um homem pode se sentir estar bem de saúde, mas nunca saber se realmente está bem de saúde. A ausência do sentimento de estar doente permite apenas à pessoa expressar que está bem na aparência. Em certa medida, permanece o fato de que a saúde é geralmente considerada como o maior bem e o fundamento de todas as atividades humanas. Sua etimologia grega, saos ou completude, ajuda-nos a recordar tal fato.

Nestas condições, não surpreende que, pelo menos na França, a história da Saúde surgiu quando a história social se interessou pelos modos de vida na sociedade e nos seus níveis, ou seja, pela saúde individual e coletiva, resultando de um desenvolvimento, que é econômico, de uma estratificação social e de atitudes culturais diversificadas. Apenas a análise da saúde nos permite levar em conta as três dimensões de nossa identidade: a do sagrado, a do sábio e a do econômico (a civilização material). Sua síntese resulta na essência do Homem, ou dos sentidos apontados acima: a Medicina.

Cuidadores e cuidados, somos dotados de uma especificidade tipicamente humana: a arte de emitir e de receber, de analisar e de sintetizar, de ser produto e produtor de nós mesmos por meio de um esforço de reflexividade referente às nossas diversas trajetórias e ao nosso percurso em comum. Naturados e naturantes, tentamos nos colocar de acordo com a natureza que está em nós e com a natureza que nos cerca. Em suma, a profissionalização de nosso "instinto de cura” pode ver o seu sucesso em uma medicalização, tanto interna quanto externa. Igualmente, a História nos convida a um diálogo com o si próprio, com o outro que está em nós, e com os dois reunidos. Esta procura sem fim da verdade não acontece sem uma con- quista e uma reconquista. O saber histórico acumulado serve ao nosso conhecimento. Conseqüentemente, a história da saúde conhece quatro principais eixos de pesquisa: o conhecimento dos profissionais de saúde, oficiais e oficiosos; o reconhecimento da parte de doença que está em nós, na nossa própria saúde; a percepção de nossa hospitalidade, o acolhimento do hóspede realizado pelo próprio hóspede, “a terra é um vasto hospital”; a identificação daquilo que nos caracteriza: a unidade e a diversidade, a estabilidade e a evolução de nossa própria dinâmica, ao fazermos a história das mentalidades, dito de outro modo, por ela se referir às nossas atitudes diante do amor, da amizade, do elo social, da vida e da morte.

\section{A história dos profissioais de saúde}

Uma primeira brecha no "monopólio" médico da história da medicina se abre com o estudo diacrônico da profissão médica, e depois das diferentes profissões da saúde. Jacques Leonard ${ }^{1}$ foi o primeiro historiador francês que estudou em detalhe a ideologia, o estatuto social e a vida cotidiana dos médicos do oeste (da França) durante um longo século XIX (1803-1892). Neste campo, ele inaugura uma pesquisa com base informática (1968-1976) e constitui um arquivo de todas as informações disponíveis sobre o corpo médico da província. Desde então, os médicos apareceram não mais como um bloco mas em toda a sua diversidade: econômica, social, científica e cultural; e isto desde o médico desconhecido até o doutor o mais eminente. Até o decênio de 1970, "as árvores escondiam a floresta", dito de outro modo, as biografias de médicos célebres escondiam a floresta dos "anônimos" e da "ralé" médica. Mais ainda, a profissionalização aparece antes da monopolização da medicina pelo corpo médico. Em outros termos, uma terapêutica médica, amplamente ineficaz aos nossos olhos do século XXI, foi imposta antes mesmo 
de ter adquirido suficiente base científica para estabelecer um consenso entre os membros do corpo médico ou, mesmo, em toda a população francesa.

Emparelhando com este primeiro estudo histórico sobre o corpo médico, exclusivamente masculino, na França até 1875, outras pesquisas, de inspiração feminista, se seguiram. Elas se interessaram pelas profissões femininas de saúde e, em particular, quanto às enfermeiras ${ }^{2,3}$. Tais estudos demonstraram que a referência à religião cristã foi substituída pelo saber e competência profissionais, mesmo se prevaleceram durante muito tempo as imagens tradicionais da mulher, santa, prestativa e representante de um "segundo sexo" que não teve acesso, por muito tempo na França, aos estudos universitários.

Pertencem igualmente a este setor as histórias de outras profissões de saúde, as partei$\operatorname{ras}^{4,5,6}$, as massageadoras fisioterapeutas ${ }^{7}$ e, enfim, as terapeutas ocupacionais. No que concerne a todos esses profissionais de saúde, a questão principal que foi abordada se refere à relação entre a formação, o estatuto jurídico, a função social e a identidade profissional, considerada aqui no quadro da sociedade francesa. Em suma, o acento foi e continua colocado sobre a legitimidade de uma relação hierárquica entre cuidados e medicina, terapeutas e médicos.

\section{Demografia, biologia e sociedade: as doenças}

No final do decênio 1950, uma outra corrente inovadora, a da demografia e da epistemologia históricas, permite igualmente que a história se desenvolva. A descoberta de uma massa de arquivos “adormecidos”, constituídos pelos registros paroquiais, pelos relatórios sobre “doenças epidêmicas" e pelas topografias médicas, desemboca em uma reconstituição das famílias e da população, mas também em níveis de vida, causas do falecimento, higiene e alimentação. Além disso, os historiadores-de- mógrafo se interessam pelo “Antigo Regime demográfico”, pela "transição sanitária” e pela "Revolução demográfica”. Não apenas os trabalhos individuais universitários se multiplicam durante os decênios 1960 e 1970, como também pesquisas em nível nacional são empreendidas, referentes ao final do Antigo Regime (1740-1789): pelo Instituto Nacional de Estudos Demográficos, pelo Laboratório de Demografia Histórica da Ecole des Hautes Etudes en Sciences Sociales e pelo seu Centro de Pesquisas Históricas, especialmente sob a direção de Jacques Dupâquier e de Emmanuel Le Roy Ladurie. E, no fim de 1969, aparece um número especial dos Annales Economies, Societés, Civilisations (ESC) intitulado "Biologia e Sociedade".

No mesmo domínio da história com base quantitativa, uma outra direção de pesquisa é privilegiada: a epidemiologia histórica. As grandes epidemias de peste encontram os seus historiadores: Daniel Panzac ${ }^{8}$, o doutor Jean-Noël Biraben ${ }^{9}$. Outros historiadores se interessam pela cólera, por exemplo, Patrice Bourdelais ${ }^{10}$, ou pela varíola ${ }^{11}$, ou ainda pela tuberculose ${ }^{12}$. Nestes livros, encontram-se relatados os grandes episódios epidêmicos, os danos sofridos, os remédios utilizados, assim como as atitudes políticas e sociais face ao perigo corrido.

Ou ainda, em outras obras, não é a história de uma doença de homens que é estudada mas a de um período relativamente breve $e^{13,14}$, onde grassam, lado a lado, graves doenças endemo-epidemiológicas. Estas pesquisas testemunham, para o período 1770-1790 essencialmente, a miséria fisiológica e social da grande massa de camponeses franceses. Acontece o mesmo com a antropologia física dos reservistas do serviço militar (começo do século XIX), investigação dirigida por Emmanuel Le Roy Ladurie no Centro de Pesquisas Históricas. Ajudado pela AIDS, volens nolens, o doutor Grmek $^{15}$ lhe dedica um livro à sua história. Grmek, criador do conceito de patocenose, abriu 
esta via com a sua história de AIDS.

\section{A história dos hospitais}

Criticados desde o século XVIII por certos médicos esclarecidos, os hospitais franceses, bem diferente dos de hoje em dia, foram estigmatizados por Michel Foucault ${ }^{16}$ que viu neles os grandes responsáveis pela "grande internação", a partir da criação de "hospitais gerais”, entre o fim do século XVII e o meio do século XVIII. Esta questão da "grande internação" dos pobres, dos vagabundos, dos mendigos e dos insensatos viu nascer um debate entre os seguidores da História Social e os da História conceptual. ${ }^{1,16}$. As pesquisas efetuadas por Jean Imbert ${ }^{17}$, um especialista em História do direito, pela historiadora Muriel Jeorger ${ }^{18}$ e pelo historiador Olivier Faure ${ }^{19,20}$ demonstraram que a "grande internação", se correspondia a uma ideologia política do poder real, no entanto apenas se referia a uma minoria que tinha a tendência a aceitar melhor o verão do que o inverno, pois a fome e o frio faziam-na encontrar no hospital um abrigo, uma morada e comida. Se os regulamentos internos eram bastante severos, sua fraca aplicação, um controle deficiente e a falta de pessoal tornavam bastante menos severa "a grande internação". Enfim, a diversidade dos estabelecimentos, uns pequenos e pobres, outros enormes e excepcionais como o de Paris, faz com que as medidas ditas impostas não correspondessem às práticas sociais. Sem esquecer que, no século XVII e durante a primeira parte do século XIX, os hospitais, em sua maioria, não eram medicalizados e que os médicos tinham aí um papel reduzido face às religiosas e aos notáveis que asseguravam, uns o funcionamento, outros, a gestão. $\mathrm{O}$ assim dito poder médico não é assim tão antigo como alguns afirmaram. Na realidade, ele é de outra natureza: o de cada pessoa se improvisar ela própria de médico, ou o de preferir o curandeiro ou o charlatão (automedicação), ou o de pre- ferir o doutor em medicina (hetero-medicação).

\section{A história das mentalidades}

Uma última direção de pesquisa marcou fortemente os decênios 1980 e 1990: a história das mentalidades, quer dizer, a das atitudes ante a vida e à morte, ao nascimento e à dor ${ }^{21} \mathrm{e}$ ao amor $^{22}$. Os diversos estudos por ela propiciados mostram a secularização e a individualização progressivas destas atitudes e o crescimento de uma medicalização da sociedade francesa, e com a dimensão do sagrado não fazendo senão se metamorfosear.

Três historiadores franceses das atitudes face à morte devem ser mencionados. Philippe Ariès $^{23}$, um autodidata que se autodenomina "um historiador de domingo", um historiador comunista, Michel Vovelle ${ }^{24}$ e um historiador “católico de esquerda”, François Lebrun ${ }^{25}$. Eles sublinharam a passagem de uma morte espetáculo edificante de uma tradição cristã a uma intimidade familiar da morte. O estudo de uma série de testamentos, a análise de ex-votos, entre outros exemplos, mostraram o nascimento de uma sociedade mais individualista, cada vez mais sensível ao prestígio do doutor em medicina e dos medicamentos farmacêuticos, partindo mais de uma saúde do corpo do que de uma saúde da alma.

Do mesmo modo, no domínio do nascimento e do parto, a lenta passagem da comadre à parteira, conhecedora das regras de sua arte, e depois ao médico obstetra, testemunha uma mudança de atitude que vai se generalizando. Os tempos mudam. Não está mais na ajuda mútua entre mulheres e na preocupação com o batizado. É dado lugar aos saberes anatômico e fisiológico, à higiene no sentido científico, aos gestos técnicos que podem salvar a mãe e/ ou a criança.

Uma leitura atenta dos trabalhos escritos pelos antropólogos e pelos etnólogos atuais marcou a geração de historiadores que se cen- 
tra na história das mentalidades. A inteligência dos contemporâneos, fundada em símbolos e no raciocínio por analogia entre o Corpo e a Natureza, foi revalorizada, por exemplo, por Jacques Gélis ${ }^{6}$, por Jean-Pierre Peter ${ }^{13}$ e por Michel Foucault ${ }^{26}$.

Dentro da mesma perspectiva, os usos antigos da limpeza foram melhor analisados e melhor compreendidos, por exemplo, por Georges Vigarello ${ }^{27,28}$ e por Jean-Pierre Goubert ${ }^{29}$. O temor à água, a prática da "tualete seca”, a utilização de perfumes nas pessoas da Corte ao invés de uma higiene freqüente, a valorização do excremento na cultura camponesa, não foram mais vistos como manifestações "obscurantistas”. Além disto, muitos historiadores, franceses e outros, de acordo com os antropólogos, não falam mais em termos de "resistências populares” face a um progresso onisciente. Bruxos, curandeiros, charlatões, não são mais apenas a imagem invertida do "bom médico”. Eles representam igualmente uma cultura do corpo que tem a sua razão de ser, histórica e sempre atual, não apenas em países ditos exóticos, mas também na França do século XXI!

\section{Um balanço positivo}

Assim, durante trinta anos, a pesquisa em História da Saúde na França foi marcada por quatro grandes direções: história dos profissionais da saúde, história das doenças, história dos hospitais, história das mentalidades. Sem sustentação institucional suficiente, salvo a da Delegation Générale à la Recherche Scientifique et Technique (DGRST) da EHESS e do Centre National de la Recherche Scientifique (CNRS), a história da saúde permaneceu o trabalho de individualidades marcantes que dirigiram algumas investigações coletivas assim como dissertações de Mestrado e teses de doutorado.

Se a história da saúde não é, na França, uma especialidade reconhecida pela universidade, é porque ela abarca toda a história: a do corpo, “o símbolo dos símbolos”, segundo o filósofo Merleau-Ponty, individual e coletivo, um e diverso, efêmero e imortal. "É no alimento que reside o remédio”, escreveu Hipócrates. Jean-Louis Flandrin, entre outros, o sabia, assim como todos os gourmets da terra. Ou seja, em um alimento tanto espiritual quanto terrestre, líquido ou sólido, em uma palavra, saboroso, tanto é verdade que saber provém de sapere, ou seja, um gosto pela vida que engloba e que transcende nossos cinco sentidos “aparados” pelo sentido cognitivo. Cronófagos nós somos, devoradores nós permaneceremos. A poção está no veneno; o veneno está na poção.

\begin{abstract}
This article describes how, having emerged in the last thirty years, research on History of Health in France has been marked by four great research directions: history of health professionals, history of diseases, history of hospitals, history of mentalities. It presents the state-of-the-art in each one of these directions during those decades. Finally, it points to the difficult process of being recognized as a separate specialty due to the broadness of its theme: the body.
\end{abstract}

Key words: History. Health. Health professionals. Diseases. Hospitals. Mentalities. France.

\section{REFERENCIAS}

1. Leonard J. Les médecins de l'ouest au XIXè siècle. Lille: Université Lille III; 1978. 3v.

2. Colliere MF. Promouvoir la vie. Paris: Inter-
Éditions; 1982.

3. Knibiehler Y, direction. Cornettes et blouses blanches: les infirmières dans la société française (1880-1980). Paris: Hachette; 1984.

4. Laget M. Naissances: l'accouchement avant l’âge de la clinique. Paris: Éd. du Seuil; 1982. 
5. Gélis J. L'arbre et le fruit: la naissance dans l'occident moderne: XVIè-XIXè siècle. Paris: Fayard; 1984.

6. Gélis J. La sage-femme ou le médecin: une nouvelle conception de la vie. Paris: Fayard; 1988.

7. Rémondière R. Le geste et la plume: histoire de la profession de kinesithérapeute en France [thèse de doctorat]. Paris: E.H.E.S.S.; 1996.

8. Panzac D. La peste dans l'empire ottoman: 1700-1850. Leuven: Éd. Peeters; 1985.

9. Biraben JN. Les hommes et la peste en France et dans les pays européens et méditerranéens. Paris-La Haye: Mouton; 1975. 2v.

10. Bourdelais P, RaulotA JY. Une peur bleue: histoire du choléra en France, 1832-1854. Paris: Payot; 1987.

11. Darmon P. La longue traque de la variole. Paris: Perrin; 1986.

12. Guillaume P. Du désespoir au salut: les tuberculeux aux XIXè et XXè siècles. Paris: Aubier; 1986.

13. Peter JP. Malades et maladies à la fin du XVIIIè siècle. In: Desaive JP, Goubert JP, Le Roy Ladurie E, Meyer J, Muller O, Peter JP. Médecins, climat et épidémies à la fin du XVIIIè siècle. Paris-La Haye: Mouton et EPHE; 1972. p. 135-70.

14. Goubert JP. Malades et médecins en Bretagne: 1770-1790. Paris: Klincksieck; 1974.

15. Grmek MD. Histoire du Sida. Paris: Fayard; 1995. 16.Foucault M. Histoire de la folie. Paris: Plon; 1961.

17. Imbert J. Histoire des hôpitaux en France. Toulouse: Privat; 1982.

18. Jeorger M. La structure hospitalière de la
France sous l'ancien régime. Ann Econ Soc Civilis. 1977;32(5):1025-51.

19. Faure O. Genèse de l'hôpital moderne: les hospices civils de Lyon de 1802 à 1845. Paris: Éd. du CNRS; Lyon: Presses universitaires de Lyon; 1981.

20. Faure O. La médicalisation de la société dans la région lyonnaise au 19è siècle (1800-1914) [thèse de doctorat]. Lyon: Université LumièreLyon II; 1989.

21. Rey R. Histoire de la douleur. Paris: Éd. La Découverte; 1993.

22. Flandrin JL. Les amours paysannes. Paris: Fayard; 1978.

23. Ariès P. Essais sur l'histoire de la mort en occident du Moyen Âge à nos jours. Paris: Éd. du Seuil; 1975.

24. Vovelle M. Images de l'au delà en Provence. Cahier des Annales 11. Paris: Armand Colin; 1973.

25. Lebrun F. Les hommes et la mort en Anjou aux XVIIè et XVIIIè siècles. Paris-La Haye: Mouton; 1971.

26. Foucault M. Histoire de la sexualité. Paris: Gallimard; 1976.

27. Vigarello G. Le propre et le sale : l'hygiène du corps depuis le Moyen Âge. Paris: Éd. du Seuil; 1985.

28. Vigarello G. Le sain et le malsain: santé et mieuxê tre depuis le Moyen Âge. Paris: Éd. du Seuil; 1993.

29. Goubert JP. La conquête de l'eau: l'avènement de la santé à l'âge industriel. Paris: Robert Laffont; 1986.

30. Garrier G. Histoire sociale et culturelle du vin. Paris: Larousse; 1998. 